\title{
연수생초청사업 효과성 평가
}

한국국제협력단 사업평가실1)

목차
I. 서론
II. 성과평가를 위한 평가모형
III. 국내초청연수사업의 내용과 현황
IV. 선진국 원조기관 사례 분석
V. 주요 수원국 사례 분석
VI. 국내초청연수사업의 성과평가
VII. 종료평가 및 관리데이터를 이용한 통계분석
VIII. 국내초청연수사업 개선을 위한 정책제언

\section{I. 서론}

\section{1. 연구의 목적}

○ 본 연구의 목적은 2010 년 $\mathrm{OECD} / \mathrm{DAC}$ 가입으로 한국국제협력단의 위상이 강화되고 있는 가운 데, 핵심 사업 중 하나인 국내초청연수사업의 효과성을 분석, 평가하고, 선진형 원조사업으로 전환하기 위한 정책 방향을 제시하기 위한 것임.

O 우리나라는 2010년 OECD DAC에 가입함으로써 세계 역사상 수원국에서 공여국으로 전환된 최 초의 국가가 됨.

1) 한국국제협력단 사업평가실 차은주 과장 요약-정리 
○ $\mathrm{OECD} / \mathrm{DAC}$ 국가에서 한국이 전략적 우위를 차지할 수 있는 분야는 개발경험 공유(Development Experience Sharing)로서 향후 대한민국 ODA 사업에서 교육협력, 개발경험 공유 사업의 중요 성이 매우 큼.

\section{〈개발경험 공유사업의 이론적 분석의 틀〉}

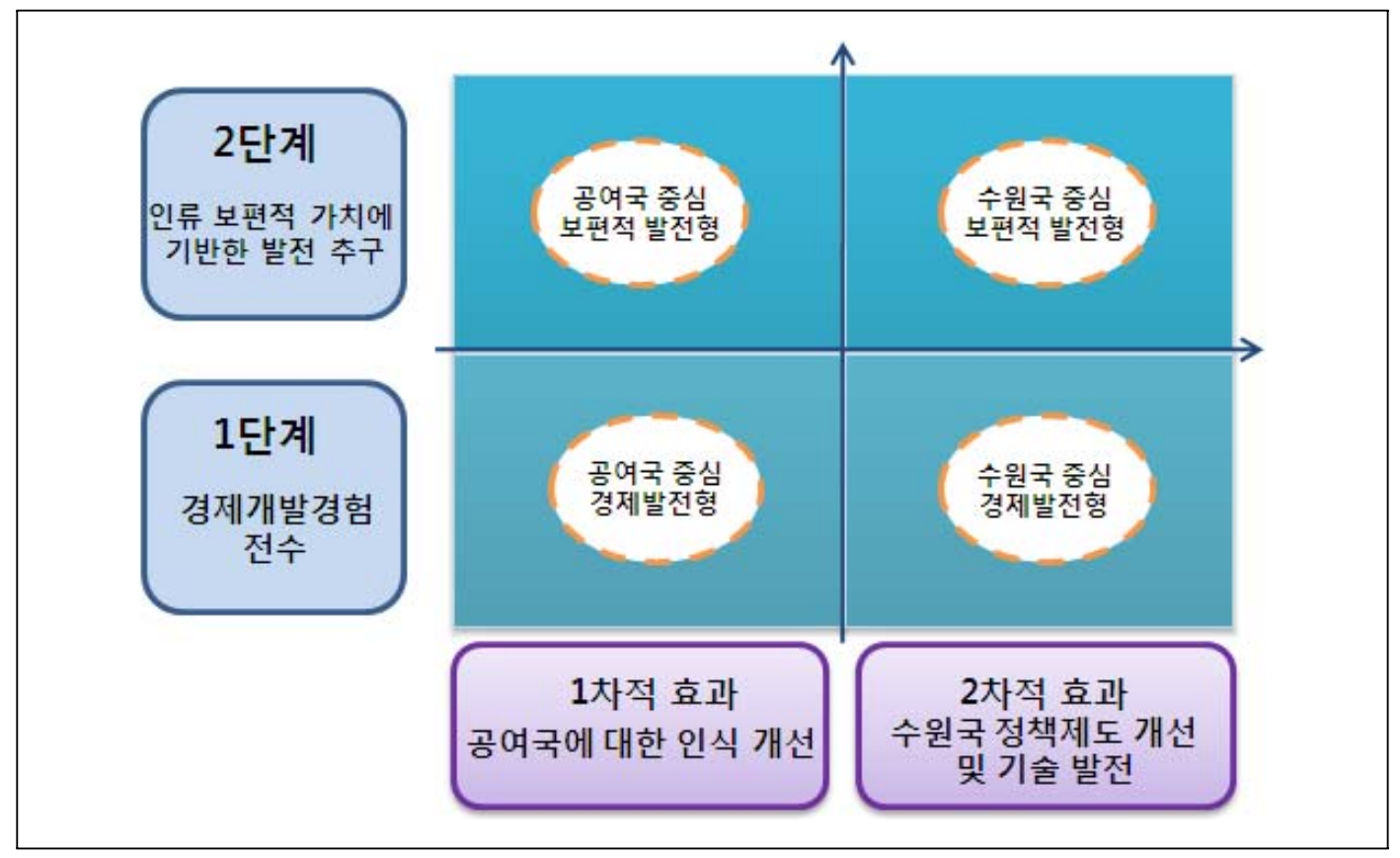

\section{2. 연구의 범위}

○〈연수사업 추진 절차 및 방법〉, 〈연수형태〉, 〈연수사업 계획 및 내용〉, 〈사후관리 프로그램〉에 대해 “적절성, 효과성, 효율성, 영향력, 지속가능성” 중심으로 평가를 실시하고 실증적 자료에 기반하여 현행 제도의 문제점과 정책 개선점을 도출할 것임.

○ 한국국제협력단 및 연수참여기관(정부기관, 정부산하기관, 대학, 민간단체 등) 관계자에 대한 조사 및 그룹토의를 통해서 현행 제도에 대해 평가하고, 연수사업의 개선점과 제언을 모색함.

○ 선진국 원조기관(JICA, SIDA)의 연수사업 현황에 대해 비교 분석함으로써, $\mathrm{DAC}$ 가입 이후 우 리나라 연수사업이 새롭게 지향해야 할 점을 제시하고자 함. 


\section{3. 평가대상 및 항목}
○ 연수사업의 추진 절차에 대한 평가
○ 연수형태에 대한 평가
○ 연수과정 내용에 대한 평가
$\bigcirc$ 사후관리에 대한 평가

\section{II. 성과평가를 위한 평가모형}

\section{1. 평가틀의 설정}

○ 본 연구는 국내초청연수사업의 평가를 위해 이상과 같은 평가기준, 평가대상 및 연수사업 이해 관계자를 포함한 평가모형을 다음과 같이 제시함.

\section{〈국내초청연수사업 평가모형〉}

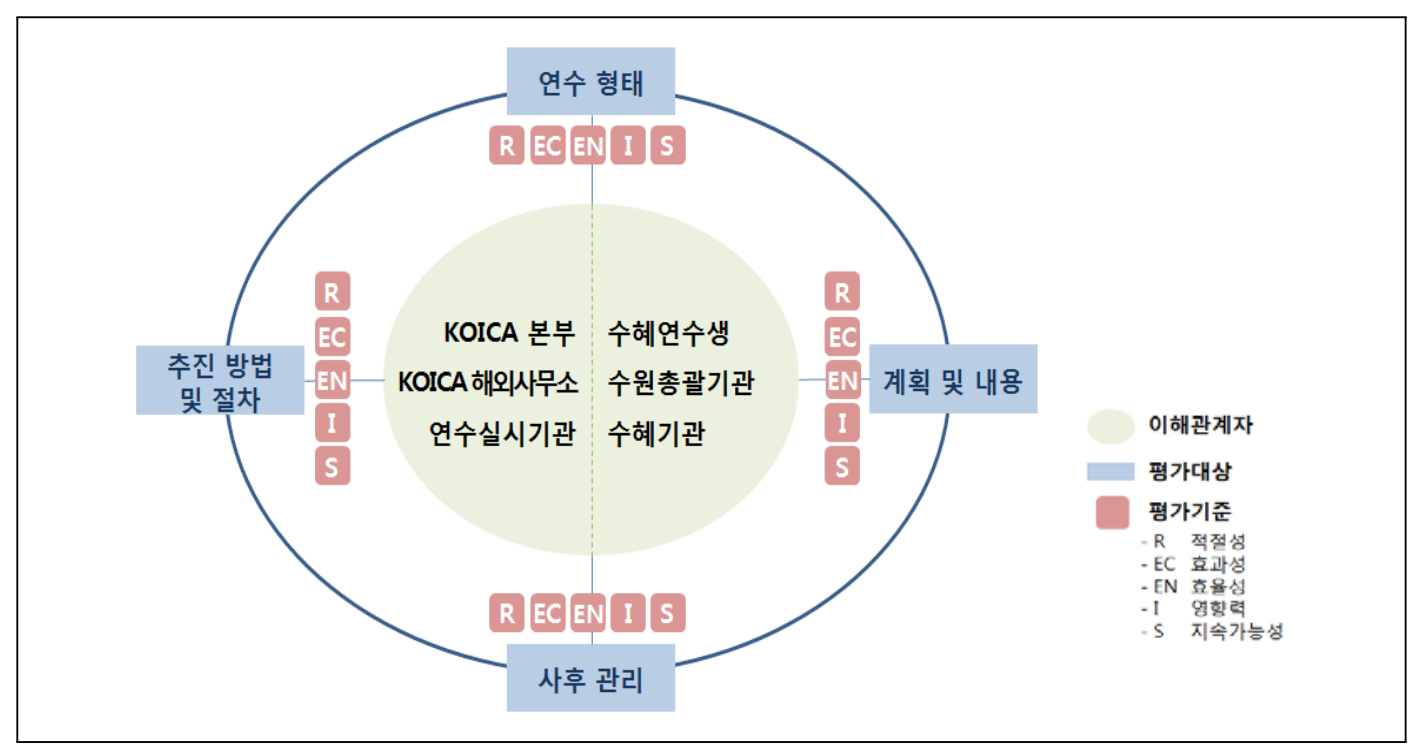

\section{2. 평가방법 및 데이터}

○ 평가모형을 적용하기 위한 조사방법으로 문헌조사, 설문조사, 면접조사 등을 사용하였음. 이러 한 다면적 조사를 통해 개별 조사방법에 내재하는 편의를 줄이고, 연수사업의 성과와 문제점을 도출하는 한편, 전문가의 조언 및 평가를 수용하는 기회가 됨. 
○ 국내초청연수사업 성과평가를 위해 연수사업 참가자 및 $\mathrm{KOICA}$ 현지사무소 직원, 수원국 연수 사업 총괄기관 담당자를 대상으로 설문조사를 실시하였음. 2007년 2009년 연수생 1,914명, $\mathrm{KOICA}$ 현지사무소 및 대사관 직원 44명, 수원국 연수사업 총괄기관 담당자 39명을 대상으로 설문조사를 실시함.

○ 문헌조사는 연수사업과 관련된 교육기관의 자체 기안자료, 자체 평가보고서, 해외 기관과 교류 한 각종 문서는 물론, 필요한 경우 강의교재 및 교과서, 수강생 만족도 조사 등 활용가능한 모 든 자료를 대상으로 하였음.

○ 면접조사는 연수총괄기관(KOICA), 연수실시기관(13개 기관), 연수생, 연수생 소속기관 관계자, $\mathrm{KOICA}$ 현지사무소 및 공관 관계자, 수원국 연수사업총괄기관 관계자, 해외원조기관(JICA, $\mathrm{SIDA})$ 등을 대상으로 실시하였음.

O 기존에 $\mathrm{KOICA}$ 종료평가보고서 작성을 위해 구축된 자료를 활용하여 통계분석을 별도로 실시 함. 통계분석은 주로 연수형태 및 연수내용에 대하여 이루어졌으며 빈도분석과 평균값 등의 기 술적 통계분석과 F검정, 회귀분석 등을 중심으로 실시함.

\section{III. 국내초청연수사업의 내용과 현황}

O 국내초청연수사업은 1963년 미국국제개발청(US Agency for International Development: USAID) 의 자금지원에 의해 수탁훈련의 형태로 시작되었으며, 1965 년 이후부터는 우리 정부의 자체예 산으로 독자적으로 실시되었음. 1991년 KOICA의 설립 이후 연수사업은 양적으로 크게 증가함.

○ 2007년의 경우, 240 개 과정에 3,340 명, 2008 년은 290 개 과정에 4,109 명, 2009 년은 243 개 과 정, 3,579 명을 교육하였음.

○ 연수형태는 국별연수, 기본연수, 특별연수, 공동연수, Scholarship Program 등 크게 5가지로 운영됨. 또한 $\mathrm{KOICA}$ 자체연수 뿐만 아니라 정부기관, 정부산하기관, 대학, 민간단체 등과 네 트워크를 형성하여 연수를 실시함. 
○ 2007년 기준으로 국내초청연수사업은 111 개 기관에서 이루어졌으며, 그 가운데 정부부처가 21 개, 정부출연기관이 51 개, 교육기관 23 개, 민간기관 및 비영리단체 14 개, 민간기업 2 개가 연수 사업을 수행함.

\section{IV. 선진국 원조기관 사례 분석}

\section{1. 일본 JICA}

○ 일본 JICA 초청연수사업은 조직구조와 특성상 한국의 $\mathrm{KOICA}$ 와 유사한 점이 많음. 사례분석 결과 다음과 같은 시사점을 발견하였음.

(1) 초청연수사업 대상의 변화 : 개인 인적개발에서 조직 정책개발로

(2) Action Plan 활용

(3) 장기적인 연수사업 예산 책정 : 3 년 단위 연수 운영

(4) 초청연수 교육자 양성

(5) 평가기준의 통일적 관리

(6) '일본식 개발정책'의 의미 재검토 : 한국형 개발모델과 보편적 가치 접목 필요

(7) 사회적 약자를 배려하는 시설 및 연수내용

(8) 사후 동문회 체계적 조직

\section{2. 스웨덴 SIDA}

O 스웨덴 SIDA의 초청연수사업(ITP)은 선진형 원조사업으로서 다단계 연수(Multi-Phased Program) 를 진행하고 있었으며, 향후 우리나라가 지향해야할 연수사업의 방향이라 할 수 있음. 사례 분 석 결과 다음과 같은 시사점을 발견하였음.

(1) 스웨덴 연수사업은 Capacity Building을 목표로 함

(2) 개인역량 강화 중심이 아니라 조직과 부문의 역량강화를 중시

(3) 다단계 프로그램(Multi-Phased Program) 운영을 통해 수원국 역량강화

(4) 〈Change Project〉를 중심으로 Case Study, Action Plan 등 참여자 중심형 교육

(5) 1 인당 예산 15,000 유로로서 우리나라의 4 배

(6) 우리나라 연수기관의 역량강화 선행되어야 함: 민간교육기관 위탁운영의 전제조건 


\section{V. 주요 수원국 사례 분석}

1. 캄보디아

○ 캄보디아의 연수사업은 캄보디아의 현실을 고려한 사업을 선정하여 운영하고 있다는 점에서 적 절성이 높은 사업이라 판단됨

○ 연수를 수행하기 전부터 일본의 시례처럼 성과계획서, Action plan 점검 및 모니터링 활동을 수행하는 것이 필요한데 이를 위해서는 한국국제협력단(KOICA) 현지 사무소에 대한 인력과 예 산을 더욱 증가시키는 것이 필요함.

○ 연수기간의 경우 단기간의 연수에서 벗어나 장기간 연수를 실시하는 것이 필요하며 일정 기간 내 재입국 금지 조항을 재검토하여 연수의 효과성을 높이는 것이 필요함.

\section{2. 탄자니아}

○ 탄자니아를 대상으로 한 연수사업은 적절성, 효율성, 효과성, 영향력, 지속가능성 등에서 소기 의 성과를 산출하는 것으로 조사됨.

O 이들은 KOICA 프로그램의 우수성으로 연수생은 물론 소속 조직의 발전에 도움이 되고 있으며, 한국의 개발 성과에 대한 벤치마킹을 통해 국가개발 전략을 개선하는 등의 긍정적 효과를 창출함.

○ 탄자니아를 중점지원국으로 설정하여 체계적이고 장기적인 계획에 의해 지원을 하고 있는 점과 함께, 아프리카 지역 가운데 상대적으로 안전한 환경, 빈곤퇴치를 위한 공공조직의 열정 등과 함께, 공용어로 영어를 사용하고 있는 수원국의 특수성도 있는 것으로 판단됨. 


\section{VI. 국내초청연수사업의 성과평가}

\section{1. 연수사업 추진절차 및 방법에 대한 평가}

○ 연수사업의 추진절차 및 방법에 대해 연수생(평균 4.18)과 연수총괄기관(평균 4.59)은 평균 4.39로 매우 만족하고 있는 것으로 나타남(설문조사는 5점 만점 기준임).

- 특히 사업 추진절차에 대한 실무작업을 담당하는 연수총괄기관의 평가가 매우 긍정적으로 나타나 현행 연수사업 추진과정이 효율적으로 운영되고 있음을 알 수 있음

○ 그러나 연수생의 경우, 다른 평가문항에 비해 상대적으로 연수사업 참여 이전의 사전과제(예: 국별보고서 등) 작성에는 다소 부정적으로 평가를 내리고 있음.

○ $\mathrm{KOICA}$ 현지사무소 및 대사관의 설문 분석결과, 현행 추진절차 등이 적절하게 이루어지고는 있으나, 특히 연수교육을 담당하고 있는 교강사의 전문성이 보다 확대될 필요가 있다고 응답하 였음.

\section{2. 연수형태에 대한 종합평가}

○ 연수형태별 평가에 있어서 전반적으로 학위과정과 공동연수에 대한 평가가 상대적으로 높게 나 타났으며 특별연수에 대한 평가가 비교적 낮게 나타남.

○ 연수형태 4가지 가운데 어떤 연수형태가 가장 효과적인지를 판단하기 위해 계층분석적 의사결 정방법(AHP)을 사용하여 분석한 결과 응답자들이 생각하는 가장 효과적인 연수형태는 '국별연 수’와 '학위과정'인 것으로 나타남.

○ 연수기간 적절성의 연수형태별 분석 결과 평균 3.42 로 타 문항 대비 상대적으로 가장 낮은 평 가가 나타남. 응답자 평균 연수기간은 42 일이나, 희망연수기간은 84일로, 전체적으로 연수기간 의 확대를 요구함. 인터뷰 결과에서도 대부분의 연수실시기관은 기본연수나, 국별연수, 특별연 수, 공동연수 등 단기연수의 문제점을 인식하고 있었음.

○ 그러나 장기연수로 전면적으로 전환하는 것은 수원국 측의 인력운용여건, $\mathrm{KOICA}$ 예산 및 연 수실시 교육기관의 역량 등 현실적 제약요건으로 인해 바람직하지 않음. 단기연수는 적은 예산 
으로 큰 효과를 거둘 수 있다는 효용성이 있으므로 단기연수의 문제점을 개선하는 방향으로 추 진해나가야 할 것임.

\section{3. 연수사업 계획 및 내용에 대한 종합평가}

○ 연수사업의 계획 및 내용 부분에 대해 응답자들은 매우 만족하고 있는 것으로 분석되었음(평균 4.28).

○ 연수내용의 업무개선 기여도가 상대적으로 낮은 편이지만, 단기연수를 통한 직접적인 업무개선 효과가 크지 않을 것을 감안한다면 절대적인 응답값은 높은 편임

○ 유의할 것은 타 공여국의 연수사업에 참여한 경험이 있는 응답자 그룹의 평가가 상대적으로 낮 은 경향을 보이고 있다는 점임. 또한 타 공여국의 연수사업에 참여한 경험이 많을수록 해당 문 항의 평가가 낮아지는 상관관계도 통계적인 유의성을 보여주고 있음.

○ 연수내용의 영향력을 평가하기 위해 연수 후 한국이미지 개선의 대륙별 분석한 결과, 연수 후 한국이미지 개선 효과는 매우 큼(4.42). 다만, 아시아권이 타 지역에 비해 다소 낮게 평가됨

\section{4. 사후관리에 대한 종합평가}

○ 전반적으로 연수생과 수원총괄기관의 연수사업 사후관리에 관한 평가는 다른 평가분야에 비해 낮게 조사됨(평균 3.89).

○ 수원총괄기관 담당자 역시 긍정적인 응답을 하고 있으나 전체 설문문항 중 가장 낮은 평가를 내리고 있음.

○ 단순히 인적 네트워크 유지라는 차원의 동문회 지원이 아니라 국별, 정책별, 기수별과 같은 체 계적인 동문회 조직개편과 지원방안을 마련해야 할 것임. 또한 연수사업의 실질적인 효과를 창 출할 수 있도록 정보교류를 지속해야 할 것임. 


\section{5. 연수사업 정책관계자의 정책제언}

○ 이상의 성과평가와 연수사업 정책관계자들과의 면접조사 결과를 종합하여 다음과 같은 정책제 언을 도출하였음.

○ 단기연수 실시기관의 정책제언

(1) 연수추진절차 및 방법의 개선방향 : 충분한 선발기간 확보와 선발과정에 해당 연수기관 참여

(2) 연수형태 : 연수형태의 다년간, 단계별 과정으로의 전환

(3) 연수계획 및 내용 : 수원국의 상황에 적합한 연수내용 강화 필요

(4) 사후관리 : 동창회 활성화 및 후속 세미나 개최 등 필요

(5) 기타 : 정책관계 기관 간 커뮤니티 활성화 및 $\mathrm{ODA}$ 홍보 필요

○ 장기연수 실시기관의 정책제언

(1) 연수추진절차 및 방법의 개선방향 : 우수연수생 선발강화 및 연수 장기계약 운영

(2) 연수형태 : 장기연수기관의 선택과 집중 필요

(3) 연수계획 및 내용 : 대학별 교육내용 특성화

(4) 사후관리 : 별도의 예산지원 필요

(5) 기타 : KOICA 담당자의 잦은 교체 지양과 사업 지원 금액 현실화

○ 연수총괄기관(KOICA 연수사업부)의 정책제언

(1) 다년도 사업 수행 방식으로 개편 필요

(2) 연수추진 시 수원국의 수요를 반영하기 위한 노력 강화 필요

(3) 연수생 선발절차 시 충분한 기간 확보 필요

(4) 연수실시기관의 전문성 강화 필요성

(5) 연수사업의 질적 강화 필요성

(6) 부처별 이해관계 조정에 있어서 $\mathrm{KOICA}$ 역할 강화 필요

(7) 수원국의 수요에 맞는 국별 연수 확대

(8) 한국의 특화된 연수분야를 개발할 필요

(9) 동창회 강화와 Follow-up Seminar 운영 필요 


\section{VII. 종료 평가 및 관리데이터를 이용한 통계분석}

\section{1. 연수형태별 분석}

○ 연수형태별 연수평가 전체 평균을 보면 공동연수가 90.5 점으로 가장 높았으며 특별연수가 89.2점으로 가장 낮게 나타났는데 연수형태별로 큰 차이를 보이지 않으며 전반적으로 좋은 평 가를 받고 있음.

○ 연수평가의 세부지표인 타당성, 목표달성도, 효율성, 기관평가 등이 연수형태별로 90점 전후의 높은 점수를 받고 있음.

○ 연수형태별 강의평가 전체 평균을 비교해 보면 특별연수와 국별 연수가 4.49점으로 가장 높았 으며 공동연수가 4.45 점으로 가장 낮게 나타남.

\section{2. 연수분야별 분석}

○ 연수에 대한 평가를 종합해 볼 때 타당성이 92.01로 가장 높은 값을 가지며 목표달성도가 89.52로 그 다음으로 높은 것으로 나타남. 연수기관에 대한 평가에서 표준편차가 가장 높고 최 소값이 50점으로 나타나 연수기관 평가에서 편차가 큰 것으로 나타남.

은연사업은 2007년 대비 2008년 연수평가와 강의평가가 모두 개선된 것으로 판단됨. 연도별로 연수와 강의에 대한 평가에서 유의미한 차이를 보이는 것은 타당성, 효율성, 목표달성도, 기관 평가, 강의시간과 같은 변수인 것으로 나타남. 이들 값들은 모두 2007년에 비해 2008년이 높 은 값을 가지는데 이는 연수가 지속적으로 개선되었음을 의미하는 것임. 연수사업은 타당성과 목표달성도가 높은 값을 가져 수원국의 인적자원개발에 높은 효과를 보인다고 판단됨.

\section{3. 기관유형별 분석}

○ 기관유형별 연수평가에서 연수실시기관에 따라 평가 결과가 상이하게 나타남. 정부기관, 공기 업 등의 평가점수가 높고 민간부문과 교육기관의 평가점수가 낮음

- 타당성 평가결과를 비교해 보면 자체실시와 공기업/정부산하기관이 92.3점으로 가장 높았으 며 교육기관이 91.0 점으로 가장 낮음. 
- 목표달성도는 정부부처가 90.2점으로 가장 높았고 교육기관이 88.7점으로 가장 낮음

- 효율성은 정부부처가 89.6점으로 가장 높았고 민간부문이 88.7점으로 가장 낮음.

○ 기관유형별 강의평가에서도 정부부문이 높고 민간부문이 낮은 점수가 나타남.

- 필요성을 기관유형별로 비교해 보면 정부부처가 4.68점으로 가장 높았으며 민간부문과 자체 실시가 4.56점으로 가장 낮게 나타남.

- 적합성은 정부부처와 교육기관이 4.53점으로 가장 높았으며 민간부문이 4.42점으로 가장 낮음.

- 이해도는 정부부처가 4.49점으로 가장 높았으며 민간부문과 자체실시가 4.36점으로 가장 낮음.

\section{4. 회귀분석}

○ 연수평가를 회귀분석한 결과 유의미한 효과가 있는 것으로 나타난 변수는 다음과 같음.

- 연수의 타당성에 대해서는 연도와 연수인원(여), 연수의 목표달성도에 대해서는 연도, 연수 의 효율성에 대해서는 연도와 연수대상국수, 기관평가에 대해서는 연도, 연수평가 종합점수 에 대해서는 연도가 유의미한 영향을 미치는 변수로 나타남.

○ 강의평가를 회귀분석한 결과 유의미한 효과가 있는 것으로 나타난 변수는 다음과 같음.

- 필요성에 대해서는 연수인원(남)과 기관유형(정부부처), 적합성에 대해서는 기관유형(정부부처), 이해도에 대해서는 기관유형(정부부처), 강의시간에 대해서는 기관유형(정부부처, 공기업/정 부산하, 교육기관), 교재에 대해서는 기관유형(정부부처, 공기업/정부산하), 만족도에 대해서 는 기관유형(정부부처, 공기업/정부산하, 교육기관), 강의평가 종합점수에 대해서는 기관유 형(정부부처, 공기업/정부산하, 교육기관)이 유의미한 영향을 미치는 변수로 나타남.

\section{VIII. 국내초청연수사업 개선을 위한 정책제언}

○ 본 연구는 $\mathrm{OECD} \mathrm{DAC}$ 에서 제시한 적절성, 효율성, 효과성, 영향력, 지속가능성 등의 다섯 가 지 평가 기준을 중심으로, 연수 추진절차, 연수형태, 계획 및 내용, 사후관리 등을 평가대상으 로 하여 분석을 실시하였음.

○ 본 연구의 분석결과는 국내초청연수사업이 성공적으로 운영되고 있다는 것으로 나타났음. 연수 추진 절차에 있어서는 수원국의 연수생, 연수총괄기관 모두 높은 만족도를 보였음. 그러나 사 
전준비 기회, 연수기간의 적절성에 대해서는 상대적으로 낮은 만족도를 보이고 있음.

○ 연수생들이 연수를 받은 이후 한국에 대한 이미지가 매우 효과적으로 개선되었다는 점에서 연 수사업의 성과가 높게 나타났음.

○ 연수를 받은 참여자들은 연수의 내용이 수원국 경제, 사회개발에 적절한 것들이었다고 평가함.

○ 이러한 긍정적인 평가에도 불구하고 한국의 국내초청연수사업은 선진형 사업으로 자리매김하기 위해서는 더 많은 노력이 필요하다고 보임.

○ 한국의 국내초청연수사업은 “공여국 중심의 경제발전형”에서 “공여국 중심의 보편적 발전형” 사이에 존재하는 것으로 판단됨. 향후에는 수원국 주도의 개발협력을 위한 노력을 더욱 기울여 야 할 것임.

○ 연구 결과 다음과 같은 정책제언을 제시함.

- 선진형 연수사업을 위한 정책목표 개선방안

- 개도국의 능력향상(Capacity Building)을 목표로 참여형·문제해결형 연수 도입

- 개인역량 강화를 넘어선 조직과 부문의 역량강화

- 연수사업 추진체계 개선방안

- $\mathrm{ODA}$ 거버넌스의 구축방향 : 다수부처 소관 엄브렐러 형

- $\mathrm{KOICA}$ 의 총괄집행기관 역할 정립

- 추진절차 및 방법 개선방안

i ) 분권화 및 지원체제들 간 의사소통 강화

ii) 연수 실시기관 간 정보교류 활성화

iii) 현지 전문가 및 현지답사 필요

- 연수프로그램 개선방안

- 연수형태 개선방안

i ) Multi-Phased Program(다단계 프로그램) 운영

ii) 국별연수 확대

- 자기주도적 참여형 교육 방식 강화

- 연수사업을 위한 전문가 양성

- 연수실시기관 역량 강화방안 : 중장기 연수계약

- 연수사업 효율화 방안 
i ) 장기적인 연수사업 예산 책정

ii) 연수사업 효율성 강화를 위해 1 인당 연수비용 증액, 연수과정 구조조정 필요

- 사후관리 및 평가체계 개선방안

- 지속가능성에 초점을 둔 사후관리의 개념 재정의: 사후 현지세미나 도입 필요

- 사업 평가체계 개선방안 : 연수기관 대상 정기 평가 필요 